\title{
Systemic candesartan reduces brain angiotensin II via downregulation of brain renin-angiotensin system
}

\author{
Nicolas Pelisch ${ }^{1}$, Naohisa Hosomi ${ }^{1}$, Masaki Ueno ${ }^{2}$, Hisashi Masugata ${ }^{3}$, Koji Murao ${ }^{4}$, Hirofumi Hitomi ${ }^{5}$, \\ Daisuke Nakano ${ }^{5}$, Hiroyuki Kobori ${ }^{6}$, Akira Nishiyama ${ }^{5}$ and Masakazu Kohno ${ }^{1}$
}

The renin-angiotensin system has an important function in the regulation of blood pressure as well as in pathophysiological processes in the central nervous system. We examined the effects of the angiotensin receptor blocker candesartan (10 $\mathrm{mg} \mathrm{kg}^{-1}$ per day, p.o.) on brain angiotensin II levels in angiotensin II-infused hypertensive rats. Angiotensin II or vehicle was infused subcutaneously for 14 days in Sprague-Dawley rats. Angiotensin II infusion resulted in increased blood pressure, an effect that was blocked by candesartan treatment. There was no effect of the angiotensin II infusion on Angiotensin II levels in the brain or on blood-brain barrier permeability. Brain tissue angiotensinogen and angiotensin converting enzyme mRNA levels were not changed by angiotensin II infusion but were decreased by candesartan treatment. At 2 weeks of treatment, CV11974, an active form of candesartan, was detectable in the plasma but was not detectable in brain tissue. These data suggest that treatment with candesartan decreases brain angiotensin II by decreasing brain angiotensinogen and angiotensin converting enzyme gene expression.

Hypertension Research (2010) 33, 161-164; doi:10.1038/hr.2009.200; published online 27 November 2009

Keywords: angiotensin II; AT1 type 1 receptor; brain; candesartan

\section{INTRODUCTION}

The renin-angiotensin system (RAS) has an important function in the regulation of systemic vascular resistance and blood pressure. ${ }^{1,2}$ The main active factor of the RAS, angiotensin II (AngII), is produced from angiotensinogen (AGT) through enzymatic cleavage by renin and angiotensin converting enzyme (ACE). ${ }^{3}$ The existence of RAS components in the brain has been well established. ${ }^{4}$ The central nervous system response to AngII has been demonstrated by intracerebral ventricular infusion of AngII, which elicited subsequent cardiovascular and dipsogenic responses. ${ }^{5,6}$ Besides AngII, other RAS components are also synthesized and distributed throughout the brain. ${ }^{7,8}$ AGT and the AngII receptors are highly expressed in glial and endothelial cells, cells are found throughout the brain. ${ }^{9,10}$ By contrast, the expression of AGT and angiotensin receptors in neurons is restricted to specific areas such as the subfornical organs. ${ }^{11}$

AngII exerts most of its actions through two receptors, the angiotensin type 1 receptor (AT1-R) and the angiotensin type 2 receptor (AT2-R). Stimulation of AT1-R mediates cell proliferation, fibrosis, vasoconstriction, aldosterone release and the inflammatory response. ${ }^{12}$ The blockade of AT1-R improves cerebrovascular compliance under hypertension, and inhibits oxidative stress, pathological cerebrovascular remodeling and cerebrovascular inflammation. ${ }^{4}$
AT2-R stimulation is important for improving inflammatory vascular injury in addition to the regulation of growth, differentiation and regeneration of neuronal tissue. ${ }^{13}$ Although AT2-R expression has been demonstrated in several regions in the neonatal brain, it can also be found in the adult brain, ${ }^{14}$ particularly in certain pathological conditions such as cerebral ischemia, brain trauma and vascular remodeling, where it can reach high levels. ${ }^{15}$

We showed earlier that systemic treatment with an AT1-R blocker (ARB) decreased infarct volume and cerebral edema, and improved ischemic injury following transient focal cerebral ischemia. ${ }^{16}$ In that study, systemic ARB treatment decreased brain AngII levels in both the ischemic and nonischemic brain hemispheres. Seltzer et al ${ }^{17}$ reported that systemic ARB treatment, along with intraventricular injection of AngII, inhibited the central effects of AngII on blood pressure, vasopressin secretion and the drinking response in spontaneously hypertensive rats. These data suggest that ARB penetrates into the brain, potentially due to blood-brain barrier (BBB) injury. Although some of the effects of ARB result from blockade of AT1-R located in the endothelium of cerebral microvessels, ${ }^{18}$ it $\mathrm{ARB}$ may also cross the $\mathrm{BBB}$ and penetrate into the brain due to increased BBB permeability in cerebral ischemic models and in spontaneously hypertensive rats. In this study, we examined the effect of systemic administration of an

\footnotetext{
${ }^{1}$ Department of Cardiorenal and Cerebrovascular Medicine, Kagawa University Medical School, Kagawa, Japan; ${ }^{2}$ Department of Pathology and Host Defense, Kagawa University Medical School, Kagawa, Japan; ${ }^{3}$ Department of Integrated Medicine, Kagawa University Medical School, Kagawa, Japan; ${ }^{4}$ Department of Internal Medicine, Kagawa University Medical School, Kagawa, Japan; ${ }^{5}$ Department of Pharmacology, Kagawa University Medical School, Kagawa, Japan and ${ }^{6}$ Department of Physiology, Hypertension and Renal Center of Excellence, Tulane University Health Sciences Center, New Orleans, LA, USA

Correspondence: Dr N Pelisch, Division of Cerebrovascular Disease, Department of Cardiorenal and Cerebrovascular Medicine, Kagawa University Medical School, 1750-1 Ikenobe, Miki-cho, Kagawa 761-0793, Japan.

E-mail: nico@med.kagawa-u.ac.jp
}

Received 2 September 2009; revised 1 November 2009; accepted 2 November 2009; published online 27 November 2009 
ARB on the brain RAS in both normotensive and AngII-infused hypertensive rats.

\section{METHODS}

\section{Animals}

All experimental procedures were performed according to the guidelines for the care and use of animals established by the Kagawa Medical University. Six-week-old male Sprague-Dawley rats were randomly divided into five groups as follows: vehicle ( $5 \%$ acetic acid), vehicle+candesartan, AngII, AngII+candesartan and $\mathrm{Val}^{5}$-AngII. An additional two groups (vehicle- or AngII-infused rats) were used for analysis of BBB permeability. AngII or $\mathrm{Val}^{5}$-AngII (200 $\mathrm{ng} \mathrm{kg}^{-1}$ per min; A9525 and A2900 respectively; SigmaAldrich, Tokyo, Japan) was infused for 14 days subcutaneously using an osmotic-mini pump (Model 2002; Alzet, Cupertino, CA, USA), with or without candesartan $\left(10 \mathrm{mg} \mathrm{kg}^{-1}\right.$ per day once daily by oral gavages; Takeda Pharmaceutical Company Ltd, Osaka, Japan), for 14 days. The doses of AngII and candesartan were determined based on earlier studies. ${ }^{19,20}$ Systolic blood pressure was measured in conscious rats by tail-cuff plethysmography (BP-98A; Softron, Tokyo, Japan) every 4 days, $\sim 2 \mathrm{~h}$ after drug treatment. All animals were anesthetized with sodium pentobarbital $\left(40 \mathrm{mg} \mathrm{kg}^{-1}\right.$, i.p; Dainippon Sumitomo Pharma, Osaka, Japan) before pump implantation. Eleven animals per each group were decapitated and plasma samples were collected. Brain tissues were then removed for AngII and gene expression measurements. For BBB permeability detection, another six animals per group were anesthetized with sodium pentobarbital $\left(50 \mathrm{mg} \mathrm{kg}^{-1}\right.$, i.p.) and the brain tissue was fixed in situ with paraformaldehyde.

\section{Brain angiotensin II}

After the animals were killed, the brain tissue was quickly separated into cortex and basal ganglia samples. Brain and plasma AngII were measured by the radioimmunoassay method, as described earlier. ${ }^{21,22} \mathrm{Val}^{5}$-AngII was measured by high performance liquid chromatography, as reported earlier. ${ }^{23}$

\section{Real time RT-PCR}

Real time quantitative RT-PCR was performed with the QuantiTect Reverse Transcription Kit (205313; Qiagen, Tokyo, Japan). Primers for ACE (5'-CA GCTTCATCATCCAGTTCC- $3^{\prime}$ ), AGT ( $5^{\prime}$-TTGGGTGCTGAGGCAAATCT-3'), renin $\left(5^{\prime}\right.$-TTGTGTGAGGAGGGCTGTAT- $\left.3^{\prime}\right)$ and GAPDH $\left(5^{\prime}\right.$-TGAACGGG AAGCTCACTGG-3') were used.

\section{Analysis of BBB permeability}

BBB permeability was quantified as horseradish peroxidase (HRP) leakage from cerebral vessels, as reported earlier. ${ }^{24,25}$ After anesthesia with pentobarbital, animals were injected with HRP (50 mg per rat, type VI; Sigma Chemical, St Louis, MO, USA) through the tail vein at $30 \mathrm{~min}$ before perfusion of the brain with $2 \%$ paraformaldehyde. For light microscopy, sections were incu-

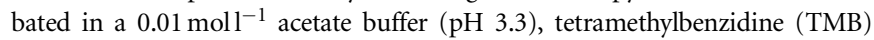
and hydrogen peroxide.

\section{Tissue and plasma CV11974 concentration}

The concentrations of CV11974 in brain tissue and plasma were evaluated by high performance liquid chromatography, as reported earlier. ${ }^{26}$ To confirm the quality of CV11974 detection, CV11974 solution mixed with a sample of brain tissue or plasma from untreated rats $\left(10 \mathrm{ng} \mathrm{g}^{-1}\right.$ for brain tissue, $5 \mathrm{ng} \mathrm{ml}^{-1}$ for plasma) was used. CV11974 concentrations of mixed samples of brain tissue or plasma with CV11974 were 9.03 and $10.3 \mathrm{ngg}^{-1}$, or 4.97 and $5.00 \mathrm{ng} \mathrm{ml}^{-1}$ ( $n=2$ per group), respectively, suggesting that the sample preparation of rat plasma and brain tissue did not affect the measured CV11974 concentration.

\section{Statistical analysis}

Values are presented as mean \pm s.d. Differences in changes in blood pressure and body weight between the groups were examined by repeated measures analysis of variance (ANOVA). Differences in AngII concentration and mRNA levels were examined by one-way ANOVA. When the overall ANOVA $P$-values were $<0.01$, Bonferroni's correction for multiple comparisons was used to assess individual group differences.

\section{RESULTS}

Blood pressure and body weight

In vehicle-infused rats, treatment with candesartan decreased systolic blood pressure, whereas AngII-infusion alone caused an increase in systolic blood pressure (Table 1); $\mathrm{Val}^{5}$-AngII-infused rats showed a similar hypertension (data not shown). In AngII-infused rats, candesartan treatment prevented the AngII-mediated increase in systolic blood. All groups showed similar body weight during the experimental period (Table 2).

\section{Angiotensin II levels in plasma and brain tissue}

As expected, the plasma AngII concentration was significantly increased in the AngII-infused rats compared with vehicle-infused rats (Figure 1a). Candesartan treatment had no effect on plasma AngII levels in vehicle- or AngII-infused rats. In vehicle-infused rats, systemic treatment with candesartan decreased brain AngII contents, whereas systemic AngII infusion alone had no effect (Figure 1b). In AngII-infused rats, candesartan treatment decreased the brain AngII contents. $\mathrm{Val}^{5}$-AngII was undetectable in the brain tissue of $\mathrm{Val}^{5}$-AngII-infused rats (data not shown).

\section{Brain RAS components}

$A G T$, renin and $A C E$ mRNA levels were measured in the basal ganglia (Figure 2). There was no effect of AngII infusion on AGT mRNA levels in the basal ganglia. By contrast, candesartan treatment for 14 days decreased the levels of AGT mRNA in the basal ganglia. Brain renin mRNA was not altered by AngII infusion or by candesartan treatment. There was no effect of AngII infusion on ACE mRNA expression. However, candesartan treatment significantly reduced ACE mRNA levels in the basal ganglia of both vehicle- and AngII-infused rats.

\section{BBB permeability}

The HRP-TMB reaction, an indicator of BBB permeability, was analyzed by light microscopy. No reactive signal was found in the vessels along the hippocampus in vehicle- or AngII-infused rats (Figure 3), despite the fact that systolic blood pressure was $>200 \mathrm{~mm} \mathrm{Hg}$ in AngII-infused rats. No signal for HRP was observed in the cerebral cortex or corpus callosum in any group.

\section{CV11974 concentrations in plasma and brain tissue}

We investigated whether CV11974, the active form of candesartan, ${ }^{27}$ could cross the intact BBB by measuring its concentration in the plasma, cerebral cortex and basal ganglia. After 14 days of candesartan treatment (10 $\mathrm{mg} \mathrm{kg}^{-1}$ per day, once daily by oral gavage), CV11974 was detectable in the plasma of candesartan-treated animals $\left(12 \mathrm{ng} \mathrm{ml}^{-1}\right)$. However, CV11974 was undetectable in brain tissue (data not shown). The minimum detection level of CV11974 was $0.5 \mathrm{ng} \mathrm{g}^{-1}$ tissue using our method (data not shown).

Table 1 Systolic blood pressure

\begin{tabular}{lllll}
\hline Groups & Day O & Day 3 & Day 7 & Day 13 \\
\hline Vehicle & $114 \pm 3$ & $118 \pm 5$ & $120 \pm 5$ & $123 \pm 4$ \\
Vehicle+candesartan & $116 \pm 5$ & $115 \pm 4$ & $109 \pm 3^{*}$ & $105 \pm 5^{*}$ \\
Angll & $117 \pm 3$ & $130 \pm 5^{*}$ & $150 \pm 5^{*}$ & $201 \pm 5^{*}$ \\
Angll+candesartan & $114 \pm 3$ & $122 \pm 4$ & $128 \pm 5^{\dagger}$ & $136 \pm 3^{* \dagger}$ \\
\hline
\end{tabular}

Values are expressed as mean \pm s.d.

${ }^{*} P<0.01$ vs. vehicle. ${ }^{\dagger} P<0.01$; Angl| vs. Angll+Candesartan. 
Table 2 Body weight

\begin{tabular}{lcccc}
\hline Groups & Day O & Day 3 & Day 7 & Day 13 \\
\hline Vehicle & $150 \pm 5$ & $202 \pm 5$ & $275 \pm 4$ & $312 \pm 3$ \\
Vehicle+candesartan & $153 \pm 4$ & $200 \pm 4$ & $267 \pm 6$ & $305 \pm 3$ \\
Angll & $149 \pm 4$ & $205 \pm 7$ & $259 \pm 5$ & $298 \pm 4$ \\
Angll+candesartan & $152 \pm 5$ & $199 \pm 5$ & $260 \pm 4$ & $301 \pm 6$ \\
\hline
\end{tabular}

Values are expressed as mean \pm s.d.
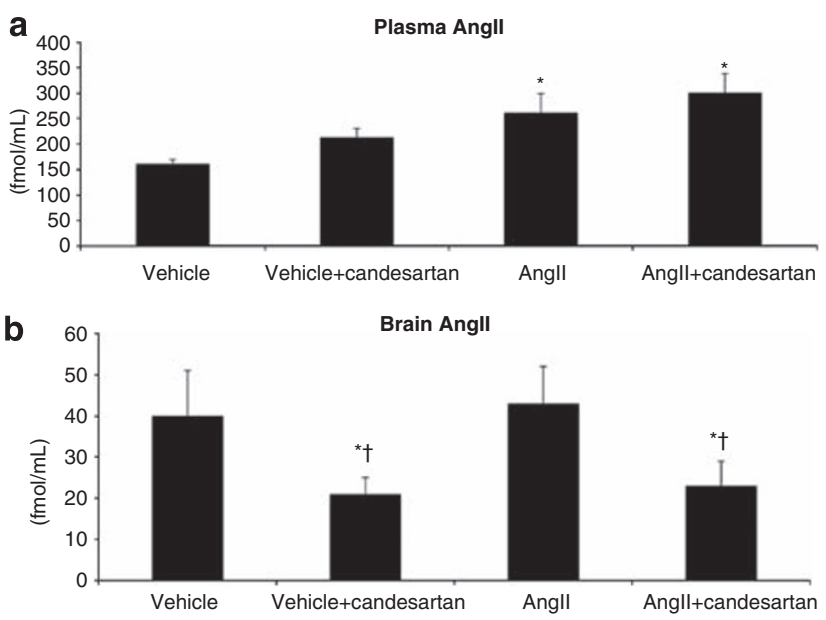

Figure 1 Plasma (a) and brain tissue (b) Angll levels. The plasma Angll concentration increased after 14 days Angll infusion. However, there was no effect on brain Angll levels. Candesartan treatment decreased brain AngII in the basal ganglia compared with both vehicle- and Angll-infused rats. ${ }^{*} P<0.01$ vs. vehicle; $† P<0.01$ vs. Angll.

\section{DISCUSSION}

In this study, we showed that in both normotensive and AngII-infused hypertensive rats, systemic ARB treatment (candesartan) for 14 days decreased blood pressure, which was associated with decreased brain AngII levels. Continuous AngII infusion increased plasma AngII concentration, but did not change brain AngII levels. In addition, labeled AngII ( $\mathrm{Val}^{5}$-AngII) was undetectable in the brain tissue after 14 days of infusion, suggesting that systemic AngII may not penetrate into the brain. We also analyzed the permeability of the BBB using the HRP-TMB reaction method. AngII-infused rats did not show any leakage in the brain microvasculature, despite a rise in blood pressure of over $200 \mathrm{~mm} \mathrm{Hg}$. Finally, the levels of the active form of candesartan in the brain were undetectable in rats treated with systemic candesartan. These data suggest that ARB does not penetrate into the brain in normotensive or systemic-AngII-treated hypertensive rats.

Earlier studies have shown only a limited ability of systemic ARB to cross the BBB. ${ }^{17,28}$ In this study, CV-11974, the active form of candesartan, was undetectable in brain tissue after oral candesartan treatment, suggesting that candesartan may not cross the intact BBB in its active form, or it may reach the brain at undetectable levels. As some parts of the brain lack the BBB, such as circumventricular organs, further investigation is needed to evaluate whether systemic ARB treatment modulates the brain AngII production heterogeneously. AT1-R is expressed on the brain vessel wall ${ }^{29}$ and AGT is known to be synthesized in astrocytes and endothelial cells. ${ }^{30,31}$ As such, ARB may block AT1-R on the brain vessel wall and downregulate AGT gene expression in astrocytes or endothelial cells. In this
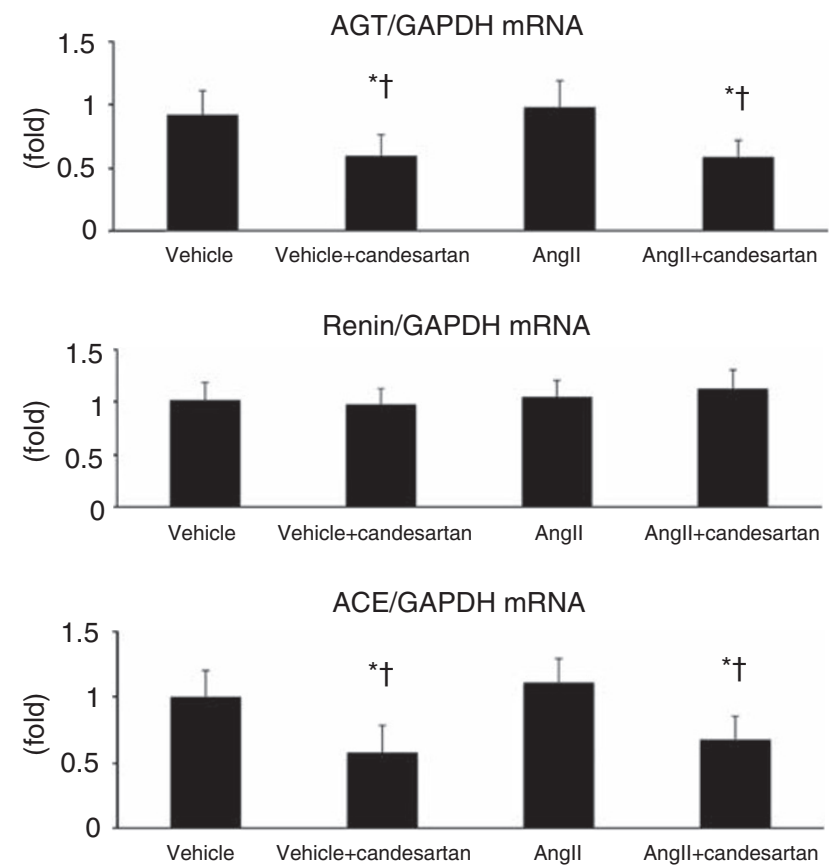

Figure 2 AGT, renin and ACE mRNA expression in brain tissue. Angll infusion did not alter AGT mRNA expression. However, candesartan treatment significantly decreased AGT mRNA in the basal ganglia of both vehicle- and Angll-infused rats. Similarly, ACE mRNA expression was unaltered by Angll infusion but was significantly decreased in the basal ganglia of both vehicle- and Angll-infused rats treated with candesartan. Although renin mRNA expression was detectable in the brain, there were no differences between the groups. ${ }^{\star} P<0.01$ vs. vehicle; $† P<0.01$ vs. Angll.
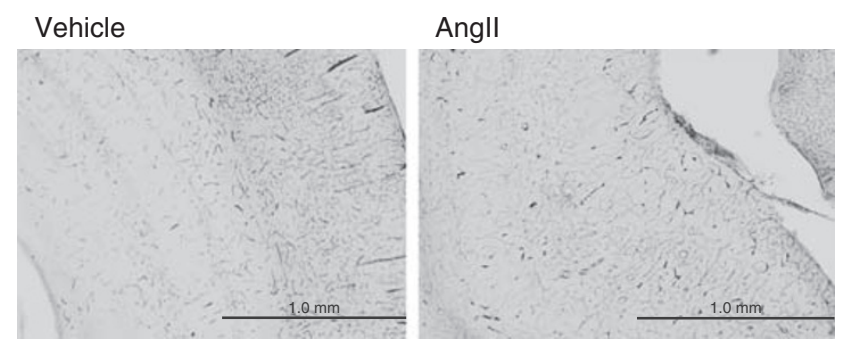

Figure 3 HRP-TMB reaction (BBB permeability). Photomicrographs of coronal sections showing the HRP-TMB reaction in vehicle- (a) and Angllinfused rats (b). No HRP-TMB reaction was observed along the microvessels of the hippocampus or the cortex of either vehicle- or Angll-infused rats.

study, candesartan treatment decreased AGT and ACE mRNA expression in the basal ganglia, which may be involved in candesartaninduced reduction in brain AngII content.

Although the AT2-R has been suggested to have a neuroprotective function in neurological diseases, including cerebral ischemia, ${ }^{15,32,33}$ little is known on the function of AT2-R in the regulation of the brain RAS. In the brain, AT2-Rs are expressed in the vascular wall and the thalamus, hypothalamus and specific brainstem nuclei. ${ }^{34}$ The reciprocal influence between the activities of AT1-R and AT2-R appears to be anatomically selective, with receptor expression modulated in some brain areas but not in others. Further studies are needed to investigate the function of AT2-R in the regulation of brain AngII during systemic ARB treatment. 
AngII injection in the brain was reported to elicit pressor effects in rats, a response that was inhibited by ARB treatment. ${ }^{6,35}$ However, the regulation of brain AngII levels by systemic ARB treatment has not been reported. Our data showed that brain AngII levels were not altered under conditions where plasma AngII levels were increased by chronic AngII infusion. However, systemic ARB treatment decreased expression of brain AngII, AGT and ACE. Although the hypotensive effects of ARB may be accompanied by downregulation of brain RAS components, further studies are needed to address the precise mechanisms involved. Indeed, it remains unclear whether ARBs need necessarily penetrate the BBB to exert their action. Although we could not detect the active form of candesartan in the brain, it is possible that undetectable levels of ARB in brain tissue would be enough to modulate the brain RAS. Alternatively, blockade of AT1-R in the cerebrovasculature by ARB may decrease ACE and AGT gene expression in brain tissue.

In conclusion, our data suggest that brain AngII is regulated in a manner distinct from circulating AngII levels. In addition, systemic ARB treatment resulted in decreased brain AngII, possibly via downregulation of brain AGT and ACE. Further studies are required to determine the precise mechanisms responsible for ARB-induced brain RAS regulation.

\section{CONFLICT OF INTEREST}

The authors declare no conflict of interest.

\section{ACKNOWLEDGEMENTS}

We express our gratitude to Ms Shiho Kobayashi and Mr Hua Fu for their technical assistance. Candesartan was kindly provided by Takeda Pharmaceutical Company Ltd (Osaka, Japan). This study was supported with the Grants in Aid for Scientific Research from the Ministry of Education, Culture, Sports \& Technology of Japan (\#18590945) to Dr Naohisa Hosomi.

1 McKinley MJ, Albiston AL, Allen AM, Mathai ML, May CN, McAllen RM, Oldfield BJ, Mendelsohn FA, Chai SY. The brain renin-angiotensin system: location and physiological roles. Int J Biochem Cell Biol 2003; 35: 901-918.

2 Paul M, Poyan Mehr A, Kreutz R. Physiology of local renin-angiotensin systems. Physiol Rev 2006; 86: 747-803.

3 Kobori H, Nangaku M, Navar LG, Nishiyama A. The intrarenal renin-angiotensin system: from physiology to the pathobiology of hypertension and kidney disease. Pharmacol Rev 2007; 59: 251-287.

4 Saavedra JM. Brain angiotensin II: new developments, unanswered questions and therapeutic opportunities. Cell Mol Neurobiol 2005; 25: 485-512.

5 Sagara Y, Hirooka Y, Nozoe M, Ito K, Kimura Y, Sunagawa K. Pressor response induced by central angiotensin II is mediated by activation of Rho/Rho-kinase pathway via AT1 receptors. J Hypertens 2007; 25: 399-406.

6 Mangiapane ML, Simpson JB. Subfornical organ: forebrain site of pressor and dipsogenic action of angiotensin II. Am J Physiol 1980; 239: R382-R389.

7 Wright JW, Harding JW. Brain angiotensin receptor subtypes in the control of physiological and behavioral responses. Neurosci Biobehav Rev 1994; 18: 21-53.

8 von Bohlen und Halbach 0 . The renin-angiotensin system in the mammalian central nervous system. Curr Protein Pept Sci 2005; 6: 355-371.

9 Morris M, Li P, Callahan MF, Oliverio MI, Coffman TM, Bosch SM, Diz DI. Neuroendocrine effects of dehydration in mice lacking the angiotensin ATla receptor. Hypertension 1999; 33: 482-486.

10 Davisson RL, Yang G, Beltz TG, Cassell MD, Johnson AK, Sigmund CD. The brain reninangiotensin system contributes to the hypertension in mice containing both the human renin and human angiotensinogen transgenes. Circ Res 1998; 83: 1047-1058.
11 Sakai K, Agassandian K, Morimoto S, Sinnayah P, Cassell MD, Davisson RL, Sigmund CD. Local production of angiotensin $I I$ in the subfornical organ causes elevated drinking. J Clin Invest 2007; 117: 1088-1095.

12 de Gasparo M, Catt KJ, Inagami T, Wright JW, Unger T. International union of pharmacology. XXIII. The angiotensin II receptors. Pharmacol Rev 2000; 52: 415-472.

13 Zhou J, Pavel J, Macova M, Yu ZX, Imboden H, Ge L, Nishioku T, Dou J, Delgiacco E, Saavedra JM. AT1 receptor blockade regulates the local angiotensin II system in cerebral microvessels from spontaneously hypertensive rats. Stroke 2006; 37: 1271-1276.

14 Reagan LP, Flanagan-Cato LM, Yee DK, Ma LY, Sakai RR, Fluharty SJ. Immunohistochemical mapping of angiotensin type 2 (AT2) receptors in rat brain. Brain Res 1994; 662: 45-59.

15 Li J, Culman J, Hortnagl H, Zhao Y, Gerova N, Timm M, Blume A, Zimmermann M, Seidel K, Dirnagl U, Unger T. Angiotensin AT2 receptor protects against cerebral ischemia-induced neuronal injury. FASEB J 2005; 19: 617-619.

16 Hosomi N, Nishiyama A, Ban CR, Naya T, Takahashi T, Kohno M, Koziol JA. Angiotensin type 1 receptor blockage improves ischemic injury following transient focal cerebral ischemia. Neuroscience 2005; 134: 225-231.

17 Seltzer A, Bregonzio C, Armando I, Baiardi G, Saavedra JM. Oral administration of an AT1 receptor antagonist prevents the central effects of angiotensin II in spontaneously hypertensive rats. Brain Res 2004; 1028: 9-18.

18 Zhou J, Ando H, Macova M, Dou J, Saavedra JM. Angiotensin II AT1 receptor blockade abolishes brain microvascular inflammation and heat shock protein responses in hypertensive rats. J Cereb Blood Flow Metab 2005; 25: 878-886.

19 Kobori H, Prieto-Carrasquero MC, Ozawa Y, Navar LG. AT1 receptor mediated augmentation of intrarenal angiotensinogen in angiotensin II-dependent hypertension. Hypertension 2004; 43: 1126-1132.

20 Nishiyama A, Seth DM, Navar LG. Angiotensin II type 1 receptor-mediated augmentation of renal interstitial fluid angiotensin II in angiotensin II-induced hypertension. J Hypertens 2003; 21: 1897-1903.

21 Nishiyama A, Seth DM, Navar LG. Renal interstitial fluid concentrations of angiotensins I and II in anesthetized rats. Hypertension 2002; 39: 129-134.

22 Fox J, Guan S, Hymel AA, Navar LG. Dietary Na and ACE inhibition effects on renal tissue angiotensin I and II and ACE activity in rats. Am J Physiol 1992; 262: F902-F909.

23 Zou LX, Imig JD, Hymel A, Navar LG. Renal uptake of circulating angiotensin II in Val5-angiotensin II infused rats is mediated by AT1 receptor. Am J Hypertens 1998; 11: $570-578$.

24 Ueno M. Molecular anatomy of the brain endothelial barrier: an overview of the distributional features. Curr Med Chem 2007; 14: 1199-1206.

25 Ueno M, Sakamoto H, Tomimoto H, Akiguchi I, Onodera M, Huang CL, Kanenishi K. Blood-brain barrier is impaired in the hippocampus of young adult spontaneously hypertensive rats. Acta Neuropathol 2004; 107: 532-538.

26 Miyabayashi T, Okuda T, Motohashi M, Izawa K, Yashiki T. Quantitation of a new potent angiotensin II receptor antagonist, TCV-116, and its metabolites in human serum and urine. J Chromatogr B Biomed App/ 1996; 677: 123-132.

27 Arnold AC, Sakima A, Ganten D, Ferrario CM, Diz DI. Modulation of reflex function by endogenous angiotensins in older transgenic rats with low glial angiotensinogen. Hypertension 2008; 51: 1326-1331.

28 Bui JD, Kimura B, Phillips MI. Losartan potassium, a nonpeptide antagonist of angiotensin II, chronically administered p.o. does not readily cross the blood-brain barrier. Eur J Pharmacol 1992; 219: 147-151.

29 Fleegal-DeMotta MA, Doghu S, Banks WA. Angiotensin II modulates BBB permeability via activation of the AT(1) receptor in brain endothelial cells. J Cereb Blood Flow Metab 2009. 29: 640-647.

30 Sherrod M, Liu X, Zhang X, Sigmund CD. Nuclear localization of angiotensinogen in astrocytes. Am J Physiol Regul Integr Comp Physiol 2005; 288: R539-R546.

31 Ide N, Hirase T, Nishimoto-Hazuku A, Ikeda Y, Node K. Angiotensin II increases expression of IP-10 and the renin-angiotensin system in endothelial cells. Hypertens Res 2008; 31: 1257-1267.

32 McCarthy CA, Vinh A, Callaway JK, Widdop RE. Angiotensin AT2 receptor stimulation causes neuroprotection in a conscious rat model of stroke. Stroke 2009; 40: 1482-1489.

33 Iwai M, Liu HW, Chen R, Ide A, Okamoto S, Hata R, Sakanaka M, Shiuchi T, Horiuchi M. Possible inhibition of focal cerebral ischemia by angiotensin II type 2 receptor stimulation. Circulation 2004; 110: 843-848.

34 Hauser W, Johren O, Saavedra JM. Characterization and distribution of angiotensin II receptor subtypes in the mouse brain. Eur J Pharmacol 1998; 348: 101-114.

35 Averill DB, Tsuchihashi T, Khosla MC, Ferrario CM. Losartan, nonpeptide angiotensin II-type 1 (AT1) receptor antagonist, attenuates pressor and sympathoexcitatory responses evoked by angiotensin II and L-glutamate in rostral ventrolateral medulla. Brain Res 1994; 665: 245-252. 